\title{
РОЛЬ ЕВРАЗИЙСКОГО БАНКА РАЗВИТИЯ В МЕЖДУНАРОДНОЙ ПРОМЫШЛЕННОЙ КООПЕРАЦИИ ГОСУДАРСТВ-ЧЛЕНОВ ЕАЭС *
}

\section{(c) 2020 Пищик Виктор Яковлевич}

доктор экономических наук, профессор Департамента мировых финансов Финансовый университет при Правительстве Российской Федерации, Россия, Москва E-mail:vpiwik@fa.ru

\section{(C) 2020 Алексеев Петр Викторович}

кандидат экономических наук, ведущий научный сотрудник Института мировой экономики и международных финансов Финансовый университет при Правительстве Российской Федерации, Россия, Москва E-mail: palekseev@fa.ru

Одним из приоритетов углубления интеграционного сотрудничества государств-членов ЕАЭС является развитие между ними производственной (промышленной) кооперации, которая призвана содействовать решению задач промышленного развития стран Союза, а также эффективной реализации их экспортного потенциала. Важная роль в решении этих задач отводится Евразийскому банку развития. В статье выявлены проблемы его инвестиционной деятельности, разработаны предложения по эффективной реализации его финансово-экономического потенциала и повышения роли в развитии промышленной кооперации государств-членов ЕАЭС.

Ключевые слова: Евразийский экономический союз; промышленная, производственная кооперация; Евразийский банк развития; цифрровая промышленная кооперация; единое цифровое промышленное пространство.

В последние годы, на основе действующей в ЕАЭС нормативной правовой базы промышленного сотрудничества (прежде всего, Основных направлений промышленного сотрудничества в рамках ЕАЭС [1] и более 100 нормативных правовых актов, принятых в их развитие), был достигнут существенный прогресс в развитии промышленных комплексов стран ЕАЭС, включая энергетику, горнодобывающую, химическую, фармацевтическую промышленность, сельскохозяйственное, транспортное машиностроение,

в том числе в рамках реализации программ импортозамещения [2]. Во многом благодаря принятым мерам, в 2014-2019 гг. наблюдается тенденция роста промышленного производства в государствах-членах ЕАЭС и в Союзе в целом (таблица 1).

Вместе с тем, как следует из таблицы 1 , рост промышленного производства в целом невысок и недостаточно устойчив (в 2015 г. наблюдалось снижение объемов промышленного производства в России, в 2015 и 2016 гг.- в Белоруссии и

Таблица 1. Индексы промышленного производства государств-членов ЕАЭС в 2014-2019 гг.,\%

\begin{tabular}{|l|c|c|c|c|c|c|}
\hline & 2014 & 2015 & 2016 & 2017 & 2018 & 2019 \\
\hline Армения & 102,7 & 105,0 & 106,9 & 112,5 & 104,3 & 109,0 \\
\hline Беларусь & 101,9 & 93,4 & 99,6 & 106,1 & 105,7 & 101,0 \\
\hline Казахстан & 100,3 & 98,4 & 98,9 & 107,3 & 104,1 & 103,8 \\
\hline Кыргызстан & 98,4 & 95,6 & 104,9 & 111,5 & 105,4 & 106,9 \\
\hline Россия & 102,5 & 99,2 & 102,2 & 102,1 & 102,9 & 102,4 \\
\hline ЕАЭС & 102,3 & 99,0 & 101,9 & 102,7 & 103,1 & 102,5 \\
\hline
\end{tabular}

Источник: Евразийский экономический союз в цифрах. Краткий статистический сборник.- М.: ЕЭК, 2019. С. 17; Аналитический обзор «Об основных социально-экономических показателях Евразийского экономического союза». Январь-декабрь 2019 г. С. 5,6. URL: http://www.eurasiancommission.org. Дата обращения: 1.09.2020.

\footnotetext{
* Статья подготовлена по результатам исследований, выполненных за счет бюджетных средств по государственному заданию Финуниверситету.
} 
Казахстане, в 2014 и 2015 гг.- в Кыргызстане). Эта неустойчивость, по нашему мнению, обусловлена наличием ряда проблем:

- низкая конкурентоспособность промышленности стран ЕАЭС, слабая структурная совместимость и взаимодополняемость их национальных экономик;

- недостаточный уровень развития промышленной кооперации в рамках ЕАЭС;

- фрагментированность единой таможенной территории ЕАЭС вследствие присоединения Республики Казахстан к ВТО с отличными от единого таможенного тарифа (ЕТТ) тарифными обязательствами по 20\% позиций (например, средний тариф по сельскохозяйственной продукции для Казахстана составляет 10,2\%, в то время как для прочих стран ЕАЭС - 17\%; по ряду товаров, в том числе чувствительных для российского рынка, уровень тарифной защиты Казахстана на 60\% ниже ЕТT [3]);

- сохранение барьеров на внутреннем рынке ЕАЭС (по данным Евразийской экономической комиссии, на 1 августа 2020 г. всего на региональном рынке сохранялись 66 препятствий, из них 15 касались технического регулирования, 13 - энергетической политики, 6 - налоговой и транспортной политики, 4 государственных закупок, 3 - промышленной политики, трудовой миграции, финансовых рынков, санитарных, ветеринарно-санитарных, карантинно-фитосанитарных мер, 2 - таможенного регулирования, торговли услугами, конкурентной и агропромышленной политики, 1 - нетарифного регулирования и внутреннего рынка [4]).
Международная производственная кооперация в рамках ЕАЭС призвана содействовать росту выпуска промышленной продукции в странах Союза, углублению региональной экономической интеграции на качественно новой основе. Важная роль в решении этих задач отводится Евразийскому банку развития. Банк в своей деятельности большое внимание уделяет развитию отраслей промышленного комплекса стран ЕАЭС. Его доля в инвестиционном портфеле Банка увеличилась с 41,2\% на 1 января 2018 г. до 48,5\% на 1 ноября 2019 г. [5].

По состоянию на 1 ноября 2019 г. текущий инвестиционный портфель ЕАБР составил 3,944 млрд. долл. и включал 96 проектов в 6 государствах-участниках Банка в различных отраслях экономики [6].

В секторе промышленного производства ЕАБР приоритетное внимание уделяет финансированию проектов в сфере энергетики, горнодобывающей, химической промышленности, машиностроении.

Хотя инвестиции в отрасли промышленности стран ЕАЭС занимают достаточно высокий удельный вес в структуре инвестиционного портфеля ЕАБР (48,5\%), тем не менее его потенциал используется недостаточно эффективно для развития внутрирегиональной производственной кооперации и интеграции. Это обусловлено, в частности, следующими факторами:

- сравнительно небольшим размером оплаченного уставного капитала ЕАБР (1,5 млрд. долл. на начало 2018 г.) [6];

- ограниченным доступом ЕАБР к инструментам получения и размещения ликвидности в

Таблица 2. Структура инвестиционного портфеля ЕАБР на 1 ноября 2019 г.,\%

\begin{tabular}{|c|c|c|}
\hline № п/п & Наименование отрасли & Доля отрасли в инвестиционном портфеле, \% \\
\hline 1. & Энергетика & 21,1 \\
\hline 2. & Горнодобывающая промышленность & 13,2 \\
\hline 3. & Химическая промышленность & 4,5 \\
\hline 4. & Машиностроение & 4,1 \\
\hline 5. & Металлургия & 3,9 \\
\hline 6. & Прочие отрасли & 1,7 \\
\hline 7. & Финансовый сектор & 0,9 \\
\hline 8. & Агропромышленный комплекс & 18,3 \\
\hline 9. & Транспорт & 15,0 \\
\hline 10. & Иная инфраструктура & 100,0 \\
\hline
\end{tabular}

Источник: Доклад о результатах ежегодного мониторинга кооперационного взаимодействия и реализации кооперационных проектов. М.: Евразийская экономическая комиссия, 2019. С. 21. URL: http://www.eurasiancommission.org. Дата обращения: 1.09 .2020$. 
национальных валютах стран-членов Банка [6];

- более высокими процентными ставками по кредитам ЕАБР по сравнению с коммерческими банками и национальными институтами развития стран ЕАЭС [7].

Исходя из вышеизложенного, для дальнейшего успешного развития международной промышленной кооперации в рамках ЕАЭС и повышения в нём роли ЕАБР необходимо акцентировать внимание на таких направлениях как:

1. Увеличение капитала и инвестиционного потенциала ЕАБР за счет эмиссии и размещения им своих облигаций на международном финансовом рынке.

2. Улучшение условий инвестиций в промышленность стран ЕАЭС путем устранения препятствий для функционирования полноценного общего рынка товаров, услуг, капиталов, рабочей силы ЕАЭС, а также восстановления единого таможенного тарифа ЕАЭС.

3. Активизация роли ЕАБР в развитии цифровой промышленной кооперации и формировании единого цифрового промышленного пространства ЕАЭС.

Рассмотрим данные направления по отдельности.

1. Увеличение капитала и инвестиционного потенциала ЕАБР за счет эмиссии и размещения им своих облигаций на международном финансовом рынке.

Основной проблемой в деятельности ЕАБР является небольшой размер оплаченного уставного капитала. По этому параметру Банк значительно уступает ведущим многосторонним банкам развития, представленным в регионе операций, например, АБР, ЕБРР, МБРР [6]. С учетом нынешней сложной финансовоэкономической ситуации в странах-учредителях ЕАБР, в настоящее время представляется едва ли реалистичным увеличить его уставный ка- питал. Повысить инвестиционный потенциал Банка, обладающего относительно высоким рейтингом, возможно за счет эмиссии и размещения им своих облигаций на международном финансовом рынке. Такой подход апробирован аналогичными международными финансовыми институтами и подтверждается, в частности, опытом Европейского инвестиционного банка (ЕИБ), созданного в 1958 г., который в последние годы расширяет масштабы своей инвестиционной деятельности, в том числе за счет активного привлечения заемных ресурсов. Так, в 2018 г. ЕИБ привлек 60 млрд. евро за счет размещения облигаций на мировом финансовом рынке. В том же году ЕИБ утвердил 854 инвестиционных проекта, при этом общий объем финансирования малого бизнеса составил 23,3 млрд. евро, 13,5 млрд. евро были направлены на стимулирование инноваций [8].

2. Улучшение условий инвестиций в промышленность стран ЕАЭС. Данное направление предусмотрено п. 4.1.2 Основных направлений промышленного сотрудничества в рамках ЕАЭС и реализуется, прежде всего, за счет финансирования Евразийским банком развития долгосрочных кооперационных проектов. Для этого разработаны необходимые нормативные правовые акты*.

Для улучшения условий инвестиций в промышленность стран ЕАЭС целесообразно продолжить работу по устранению препятствий для функционирования полноценного общего рынка товаров, услуг, капиталов, рабочей силы ЕАЭС. Также целесообразно восстановление единого таможенного тарифа ЕАЭС путем приведения в соответствие с ним практики взимания ввозных таможенных пошлин в Казахстане.

3. Активизация роли ЕАБР в развитии цифровой промышленной кооперации и формировании единого цифрового промышленного про-

\footnotetext{
* В частности, 13 января 2017 г. было принято Распоряжение Совета ЕЭК № 1 «О взаимодействии Евразийской экономической комиссии, государств-членов Евразийского экономического союза и Евразийского банка развития по вопросам, связанным с рассмотрением кооперационных проектов, имеющих интеграционный потенциал, для финансирования Евразийским банком развития». В соответствии с этим документом была утверждена Рабочая группа по рассмотрению кооперационных проектов, имеющих интеграционный потенциал, для финансирования ЕАБР. Руководителями группы являются представитель Комиссии - член Коллегии (Министр) по промышленности и агропромышленному комплексу и представитель Евразийского банка развития - Председатель Правления ЕАБР. Группа создана на высоком уровне - членами являются заместители министров экономики и промышленности государств-членов ЕАЭС. Основные задачи группы включают организацию взаимодействия между Комиссией, государствами-членами Евразийского экономического союза и ЕАБР по вопросам связанным с рассмотрением и продвижением кооперационных проектов в промышленности, выявление кооперационного потенциала в государствах-членах, обсуждение мер поддержки кооперационных проектов, выработку рекомендаций о необходимости финансирования кооперационного проекта ЕАБР.
} 
странства ЕАЭС.

Важнейшим документом, определяющим правовые основы реализации данного направления, является Решение Высшего Евразийского экономического совета от 11 октября 2017 г. № 12 «Об основных направлениях реализации цифровой повестки Евразийского экономического союза до 2025 года», в котором установлены цели, принципы, задачи, направления, механизмы сотрудничества государств-членов по вопросам реализации цифровой повестки* ЕАЭС на долгосрочный период, а также основные приоритеты данного сотрудничества**.

В соответствии с п. 4.4.1 Основных направлений промышленного сотрудничества в рамках ЕАЭС, одним из приоритетных направлений данного сотрудничества определено создание условий для цифровой трансформации промышленности в государствах-членах и формирования единого цифрового пространства промышленности [1].

В целях создания благоприятных условий для цифровой трансформации промышленности стран ЕАЭС и формирования единого цифрового промышленного пространства Союза Евразийской экономической комиссией разработаны и утверждены два базовых документа:

- Концепция создания евразийской сети промышленной кооперации и субконтрактации (утверждена Решением Совета ЕЭК от 21 декабря 2016 г. № 143);

- Концепция создания и функционирова- ния евразийской сети трансфера технологий (утверждена Решением Совета ЕЭК от 30 марта 2018 г. № 23) ****.

Федеральная корпорация России по развитию малого и среднего предпринимательства (Корпорация МСП) и ЕАБР, содействуя продвижению цифровых сервисов для предпринимателей стран-участниц ЕАЭС, 19 сентября 2019 г. подписали протокол о намерениях, направленный на внедрение на их территории геомаркетингового информационно-аналитического ресурса на базе Портала Бизнес-навигатора МСП (Портал) в целях оказания поддержки субъектам малого и среднего предпринимательства.

В настоящее время Портал охватывает 177 городов России, на нём зарегистрировано свыше 2 млн. пользователей, из них более 1,3 млн.субъекты МСП. Данная система предоставляет предпринимателям ряд возможностей, как для начала собственного бизнеса, так и для его расширения. На Портале можно узнать о степени востребованности того или иного бизнеса, предпочтительном месте его расположения, размере первоначальных инвестиций и документах, которые потребуются для его открытия. Бизнеснавигатор МСП помогает составить примерный бизнес-план, рассчитать спрос на товары и услуги, проанализировать конкурентную среду целевого рынка [5].

Предполагаемый функционал разрабатываемой Корпорацией МСП и ЕАБР цифровой системы шире создаваемых систем промыш-

\footnotetext{
* Цифровая повестка определена в Основных направлениях как «круг актуальных для Союза вопросов по цифровой трансформации в рамках развития интеграции, укрепления единого экономического пространства и углубления сотрудничества государств-членов, определенный в Заявлении о цифровой повестке Евразийского экономического союза от 26 декабря 2016 года и Основных направлениях».

** Согласно данному Решению, к основным приоритетам реализации цифровой повестки Евразийского экономического союза до 2025 года относятся: 1) цифровая прослеживаемость движения продукции, товаров, услуг и цифровых активов; 2) цифровая торговля; 3) цифровые транспортные коридоры; 4) цифровая промышленная кооперация; 5) Соглашение об обороте данных (в том числе о защите персональных данных); 6) система регулятивных «песочниц».

**** По мнению экспертов ЕЭК, реализация данных концепций позволит создать экосистему по формированию партнерства, кооперации и субконтрактации, обеспечить вовлечение малых и средних предприятий в производственные цепочки крупных производителей, оптимальную загрузку производственных мощностей, а также стимулирование инновационных процессов путем трансфера технологий, возможности продвижения продукции субъектов промышленности на рынки третьих стран с использованием международных цифровых экосистем. Евразийская сеть предоставит доступ к территориально распределенному набору сервисов государств-членов, в том числе за счет включения сервисов кооперации и субконтрактации, трансфера технологий национальных компонентов, и большому объему консолидированной информации, необходимой для ведения хозяйственной деятельности и обеспечивающей поддержку промышленной кооперации и трансфера технологий. (В ЕАЭС будет реализован проект «Евразийская сеть промышленной кооперации, субконтрактации и трансфера технологий». URL: http://www.eurasiancommission.org/ru/nae/news/Pages/16-05-2019-1.aspx. Дата обращения: 1.09.2020).
} 
ленной кооперации и субконтрактации, а также системы трансфера технологий и нацелен на обеспечение необходимыми сервисами субъектов малого и среднего предпринимательства [5].

Представляется целесообразным повысить роль ЕАБР в формировании единого цифрового промышленного пространства ЕАЭС. Для этого следует дополнить Приложение к Рекомендации Совета ЕЭК от 3 марта 2017 г. № 2 «О перечне взаимовыгодных направлений кооперационного сотрудничества государств-членов Евразийского экономического союза с учетом целесообразности финансирования соответствующих проектов Евразийским банком развития» пунктом 9 «Создание цифровых сервисов для цифровой трансформации промышленного сотрудничества государств-членов ЕАЭС».

В целом для более эффективной реализации финансово-экономического потенциала и повышения роли ЕАБР в развитии промышленной кооперации государств-членов ЕАЭС необходимо реализовать следующие предложения:

1. В целях объективной оценки усилий ЕАБР по привлечению дополнительных средств для расширения своей инвестиционной деятельности дополнить перечень стратегических контрольных индикаторов деятельности ЕАБР показателем «Объем ресурсов, привлекаемых ЕАБР путем выпуска долговых инструментов».

2. Активизировать привлечение ресурсов с использованием широкого перечня предлагаемых Банком программ выпуска долговых инструментов, в том числе еврооблигаций и еврокоммерческих нот, с разными сроками обращения в иностранных валютах и национальных валютах государств-членов ЕАЭС, включая рубли и тенге, с двойным листингом на местных торговых площадках, например, ПАО «Московская биржа» и $\mathrm{AO}$ «Казахстанская фондовая биржа».

3. В целях создания условий для деятельности ЕАБР на финансовых рынках стран ЕАЭС, привлечения ресурсов путем размещения на них долговых инструментов (в том числе еврооблигаций и еврокоммерческих нот) следует разработать критерии евразийского финансового паспорта для банковских и небанковских организаций стран ЕАЭС и ввести его в действие для обеспечения равных возможностей ведения бизнеса финансовыми организациями на территории всех стран ЕАЭС (по аналогии с европейским финансовым паспортом для банков и финансовых компаний стран Евросоюза). Разработка и использование единоообразных, относительно строгих критериев отбора финансовых организаций стран ЕАЭС, допускаемых на национальные рынки, обеспечит устойчивое развитие создаваемого общего финансового рынка стран, снизит риски инвестиционной деятельности ЕАБР и других финансовых институтов в регионе ЕАЭС.

4. Продолжить работу по устранению препятствий для функционирования полноценного общего рынка товаров, услуг, капиталов, рабочей силы ЕАЭС.

5. Принять меры к восстановлению единого таможенного тарифа ЕАЭС путем приведения в соответствие с ним практики взимания ввозных таможенных пошлин в Республике Казахстан.

6. В интересах повышения роли ЕАБР в формировании единого цифрового промышленного пространства ЕАЭС дополнить Приложение к Рекомендации Совета Евразийской экономической комиссии от 3 марта 2017 г. № 2 «О перечне взаимовыгодных направлений кооперационного сотрудничества государств-членов Евразийского экономического союза с учетом целесообразности финансирования соответствующих проектов Евразийским банком развития» пунктом 9 «Создание цифровых сервисов для цифровой трансформации промышленного сотрудничества государств-членов ЕАЭС».

Вышеприведенные меры окажут содействие наиболее полной реализации финансовоэкономического потенциала ЕАБР в развитии международной промышленной кооперации и интеграции в рамках ЕАЭС и повышению роли Банка в реализации социально-экономических проектов России.

\section{Библиографический список}

1. Решение Евразийского межправительственного совета от 8.09 .2015 г. № 9 «Об основных направлениях промышленного сотрудничества в рамках Евразийского экономического союза» (с изменениями и дополнениями). URL: https://docs.eaeunion.org/docs/ru-ru/0148480/icd_10092015_9. Дата обращения: 1.09.2020 г.

2. Доклад «Промышленная политика в Евразийском экономическом союзе: три года интеграции».- М.: ЕЭК, 2018. URL: http://www.eurasiancommission.org/ru/Documents. Дата обращения: 1.09.2020. 
3. Глазьев С. Ю. Рывок в будущее. Россия в новых технологических и мирохозяйственных укладах. - М.: Книжный мир, 2018. С. 602.

4. URL: https://barriers.eaeunion.org/ru-ru/Pages/obstacles.aspx. Дата обращения: 2.08.2020.

5. Доклад о результатах ежегодного мониторинга кооперационного взаимодействия и реализации кооперационных проектов.- М.: ЕЭК, 2019. URL: http://www.eurasiancommission.org/ru/act/prom_i_agroprom/dep_ prom/SiteAssets/B1.pdf. Дата обращения: 1.09.2020.

6. Стратегия Евразийского банка развития на период с 2018 по 2022 год. URL: https://eabr.org/upload/data/ strategy_2018_2022.pdf. Дата обращения: 1.09.2020.

7. Тюлебеков Т.Б. Евразийский банк развития как один из инструментов региональной интеграции на постсоветском пространстве // Актуальные научные исследования в современном мире. 2019. № 11. С. 20 -24.

8. Краткий обзор деятельности Европейского инвестиционного банка. URL: www.eib.org/attachments/general/ the_eib_at_a_glance.pdf. Дата обращения: 1.09.2020. 